\title{
CLIENT EXPECTATION FROM RESIDENTIAL PROPERTY DESIGN SERVICES AND ARCHITECTS' PERCEPTION
}

\author{
OLUWATAYO, Adedapo Adewunmi \\ Covenant University-Nigeria \\ Email: dapo.oluwatayo@covenantuniversity.edu.ng
}

\begin{abstract}
Very few studies exist on the expectations of clients from architects. There are however, anecdotal evidences that architects may not fully grasp what is most important to their clients. As a pilot study, the aim of this paper was to investigate the expectations of clients from residential design services and architects' perceptions of those expectations. A questionnaire was designed to suit the purpose of comparison of responses of the two groups. The factor analysis conducted revealed that the expectations from design services could be described in terms of value, professionalism, and empathy. Using mean gap analysis, the study identified areas where architects have under-estimated the expectations of clients as well as those areas where the expectations have been over-estimated. The results would help architects to focus on areas, which are important to the clients and possibly reduce client dissatisfaction. This is study, which is one of the first on the subject, is limited in three ways. First, residential clients were the only ones considered. In addition, respondents were only taken from Nigeria and the sample size as well as the response rate was small.
\end{abstract}

Keywords: Architects, architectural design services, client expectation, architects' perception, residential property.

\section{INTRODUCTION}

A client often has a number of expectations in procuring architectural services. When these expectations are fulfilled, the client is satisfied (Hui and Zheng, 2010). Several studies have focused on client satisfaction in the construction industry (Tang, Lu, and Chan, 2003; Oyedele and Tham, 2006), which has been said to be the difference between client expectations and their perception of quality of service as observed by Hui and Zheng (2010). An important aspect in determining how architects respond to clients' needs is the accurate knowledge of what their expectations are. This is consequent on the fact that services, such as architecture, are often customized, requiring accurate assessment of client expectations. As opined by Boyd and Kerr (1998), firms in the construction industry are expected to be clientfocused, meaning that client expectation should form the basis of their service offerings.

Scholars, notably Bowen, Cattel, Hall, Edwards, and Pearl, (2002) have investigated clients' expectation of construction services. However, little is known about clients' expectations from design services. Most of the clients of architects in Nigeria commissioned them for residential services (Oluwatayo, 2009). Little research has however been little research on the expectations of those clients. This is probably the reason for the alleged low satisfaction of clients with architectural services (Oyedele and Tham,
2006). It may be a reflection of architects not having accurate perception of their clients' expectations. This may lead to inadequate focus on areas that are really important, especially with design services. It is therefore essential to identify the gaps, if any, in client expectations and architects' perceptions of those expectations. Knowledge of the identifiable gaps may enable architects position themselves for better service to meet their clients' expectations. In respect of the forgoing, the study is therefore aimed at investigating the gaps, if any, between client expectations for design services and architects' perceptions of those expectations. The aim of the study is to investigate the expectations of clients from architectural residential services. Specifically, the study answers two questions: which factors define the expectations of clients from residential design services? In addition, is there any difference in the opinions of architects and clients on the importance attached to expectations from design services?

A study nature would contribute to the service quality literature by identifying areas that are important to clients in search of residential design services. It would also identify the expectations of clients of residential architectural services and highlight the misconceptions that architects may hitherto have had on those expectations. This may enable architects to reposition to satisfy their clients

Customer or client expectation, according to Ziethalm, Berry and Parasuraman (1993) is pretrial 
beliefs about a product or service. Salehi, Alipour and Sharif (2009) put this in clearer terms by stating that expectations are what people think they would get from a service. These expectations serve as standards against which experiences are often compared. In several studies, client expectation has been investigated in relation to client satisfaction. Brown and Swartz (1989) specifically noted that service providers would design, develop, and deliver services based on their perceptions of client expectations. According to Salehi, Alipour and Sharif, (2009), service connotes experience or process and this experience, which in the context of architectural services, need to be managed by architects. To achieve this aim, the architect has the responsibility of accurately assessing the expectations of the clients in order to provide acceptable service. This has become essential as clients often evaluate services based on their individual expectations. This is moreso with architectural design services, which have to be customized to client needs. It may therefore be important to investigate if architects in Nigeria and elsewhere are able to accurately assess clients' expectations from their design services. Inaccuracies in assessing clients' expectations often result in gaps, which Salehi et al. (2009) defined as the result of the differences in opinions or perceptions between two or more groups. The intangibility nature of professional services often results in expectation gaps. This is in addition to the fact that clients of architectural firms do not often know what they want from design services.

There are however indications of certain issues that are pertinent to clients in the construction industry. These include cost, time and quality (Bowen et al. 2002). In addition to these, the service under investigation is professional, it would therefore be expected that clients would require expertise and competence, especially for design services as opined by Brown, Kornberger, Clegg, and Carter, (2010). A professional service like architecture may be expected to have a touch of creativity (Lewis, 1998), and good personal relationship (Sonne, 1999). The expectations of clients for functional design may also be very important. It may therefore be worthwhile to find out if the clients expect architects to display good experience in the field as well as provide them with a wide range of service along with the design services.

In relation to the construction industry, Bowen et al. (2002) noted that quality, cost, and time were the most important concern of clients. It was observed that when construction projects are not completed on time, they are considered as failures. Similarly, clients are concerned about efficiency in cost management and good quality services. However, further study on clients, architects, quantity surveyors, project managers, consulting engineers and general contractors in South Africa, found that clients rated the requirement for project quality higher than time, while the reverse was the case with the contractors and consultants. It will be noted that the study was carried out on construction services without focus on design services. Findings regarding study on design services may differ.

\section{RESEARCH METHODS}

Two separate surveys were carried out to achieve the objectives of this study. While the first survey targeted architects, the second targeted clients who commissioned the architects for residential design services for the first time. This resulted in two sets of data, which were compared in order to explore the issue of client expectations. The first consisted data collected from architects to determine their perceptions of clients' expectations of their design services, while the second consisted data obtained from clients. The list of Architects registered to practice in Nigeria (ARCON, 2010) shows that the highest number of architectural firms (34 percent) were located in Lagos, Nigeria. This informed the choice of Lagos as a location for the pilot study. The firms were first called to confirm their willingness to participate. Intention to participate was obtained from 50 firms to which 50 questionnaires were sent. The participating firms were asked to help in administering one (1) questionnaire to one of their clients whom they were to provide residential design services for in the last one year. This added up to 50 questionnaires administered to the clients. The data were collected concurrently between March and April 2012.

The questionnaire was designed to facilitate comparison of the responses of the two groups. The questionnaire consisted of two sections. The first section elicited information on the profiles of the respondents while the second section requested respondents (both clients and architects) to rate a number of statements concerning client expectations from design services. A 5- point Likert scale, which ranged from "Not Important" to "Highly Important", was used. Of the 100 questionnaires distributed to the two classes of respondents, the architects returned 20 questionnaires (representing 40 percent response rate) while clients returned 16 (representing 32 percent response rate). This represented $40 \%$ response rate by architects and 32\% response rate by clients. 
The Cronbach's Alpha test carried out on the variables used in measuring expectations of clients from architectural design services show that the variables were internally consistent. This is because the value obtained was 0.652 , which according to George and Mallery (2003) is acceptable. The mean ratings of the responses to the importance of factors that represent client expectations from design services were calculated. The perception gap was computed by the difference between clients' mean scores and architects' mean scores on client expectations. A positive gap result was set to indicate that the architects underestimates clients' expectations, while a negative gap result indicates that architects overestimates clients' expectations. To identify the factors that define the expectations of the clients, a factor analysis was carried out using principal component method. Varimax rotation was used to identify variables that loaded on each factor with values not less than 0.5 .

\section{RESULTS AND DISCUSSION}

Most of the architects that responded to the questionnaires were aged between 36 and 40 years, while most of the clients were aged between 46 and 50 years. The results of also show that most of the respondents were men, as presented in Table I. The results further suggest that the architect's display of competence and relevant experience were the most important expectations of the clients when it comes to residential designs (Table II). The clients rated cost effective, functional designs and good personal experience equally. Wide range of services was ranked least on the list of clients' expectation. The architects on the other hand ranked cost- effective designs as the most important client expectation from design services. The display of relevant experience, which the clients ranked as their second most important expectation of architects was ranked as the least but one important requirement.

A comparison of the scorings of the clients and architects on the client expectations from design services investigated in the study show that the gap score varied from 0.68 (display of relevant experience) to -0.2 (quality service). Specifically, the architects underestimated the clients' expectation on requirements for display of relevant experience and competence, innovation, wide range of services, good personal experience and functional design. They however overestimated the clients' expectations for timely delivery of service, cost- effective designs and quality service.
The results of the factor analysis (Table II) reveal that three factors can be used to describe client expectations from design services. These factors accounted for 71.7 percent of the variance in the data. Loading on the first factor were display of experience, comprehensive service, cost effective designs, innovation/new ideas and quality service, which can be described as value. The second factor, which accounted for 27.7 percent of the variance in the data represented professionalism and had variables such as functional design, timely service, and display of competence loading on it. One word that can be used to describe the third factor is empathy as it denotes the good personal experience that clients get in the process of service delivery. This accounted for 14.9 percent of the variance in the data. These were the dimensions by which client expectation from design services can be described.

Table 1. Profile of Respondents

\begin{tabular}{llrr}
\hline & & $\begin{array}{c}\text { Architects } \\
(\%)\end{array}$ & $\begin{array}{c}\text { Clients } \\
(\%)\end{array}$ \\
\hline Age of respondents less than 35 years & 10.0 & 0 \\
& 36-40 years & 40.0 & 12.5 \\
& 46-50 years & 20.0 & 50.0 \\
& 51-55 years & 30.0 & 25.0 \\
Gender & 0 & 12.5 \\
& 61 years and above & 80.0 & 87.5 \\
& Male & 20.0 & 12.5 \\
\hline
\end{tabular}

Source: Author's Fieldwork (2012)

The study found that the factors that define the expectation of clients from architectural design services are value, professionalism and empathy. This suggests that the clients expect more than the standard service being provided. They also expect a good personal relationship in the process. The results of the study also show that clients in search of architectural design services may actually be sure of what they expect for the service experience, contrary to the suggestion of Sonne (1999). It is interesting to note that to clients in need of residential design services, they most of all desire that the architect display competence and experience. This is probably because, as noted by Jones, Hesterley, Fladmoe-Lindquist and Borgatti (1998), architectural firms as professional service firms are always hired for their expertise and skills, which enables them to produce an outcome that the client can use. It may then follow that every client will expect architectural firms to display this rare competence, which they claim to possess, especially for design services. It may therefore not be surprising that for the clients, expertise and experience come before all else, even before issues that concern the 
Tabel 2. Analysis of Discrepancy between Client Expectations from Residential Design Services and Architects' Perceptions

\begin{tabular}{|c|c|c|c|c|c|}
\hline Factor & Variables & $\begin{array}{l}\text { Factor } \\
\text { loading }\end{array}$ & $\begin{array}{l}\text { clients' } \\
\text { expectation } \\
\text { (mean) }\end{array}$ & $\begin{array}{l}\text { architects' perception } \\
\text { of clients' expectation } \\
\text { (mean) }\end{array}$ & $\begin{array}{c}\text { Mean Gap (clients' } \\
\text { score-architects' score) } \\
\text { (SD) }\end{array}$ \\
\hline \multirow[t]{5}{*}{ Value $(29.1 \%)$} & display of relevant experience & .848 & 3.88 & 3.20 & $\begin{array}{r}0.68 \\
(0.61)\end{array}$ \\
\hline & $\begin{array}{l}\text { wide range of services/ } \\
\text { comprehensive ideas }\end{array}$ & .668 & 3.38 & 3.22 & $\begin{array}{r}0.16 \\
(0.59)\end{array}$ \\
\hline & cost effective designs & -.646 & 3.75 & 3.90 & $\begin{array}{r}-0.15 \\
(0.38)\end{array}$ \\
\hline & new ideas/innovation & .637 & 3.50 & 3.00 & $\begin{array}{r}0.50 \\
(0.65)\end{array}$ \\
\hline & quality service & .544 & 3.50 & 3.70 & $\begin{array}{r}-0.20 \\
(0.50)\end{array}$ \\
\hline \multirow[t]{3}{*}{$\begin{array}{l}\text { Professionalism } \\
(22.7 \%)\end{array}$} & functional design & .902 & 3.75 & 3.70 & $\begin{array}{r}0.05 \\
(0.46)\end{array}$ \\
\hline & timely service delivery & -.739 & 3.63 & 3.67 & $\begin{array}{r}-0.04 \\
(0.49)\end{array}$ \\
\hline & display of competence & .631 & 4.00 & 3.70 & $\begin{array}{r}0.30 \\
(0.51)\end{array}$ \\
\hline Empathy (14.9\%) & good personal experience & .921 & 3.75 & 3.60 & $\begin{array}{r}0.15 \\
(0.59)\end{array}$ \\
\hline
\end{tabular}

Source: Author's Fieldwork (2012)

residential design task itself. The architects did not however perceive that display of experience was as important to clients who commissioned them for design services. In fact, the highest gap was recorded for this issue. Architects also believed that clients would value functional designs more in residential designs than they value the display of competence by the architect. The reverse is however the case with the clients. It is not clear why architects will believe that displays of experience and competence were not so important to the category of clients sampled in this study. It is however possible that the architects may have a misconception that once they are able to deliver required service; the level of their experience or competence displayed will not matter as much.

In addition, the result shows that both clients and architects ranked cost- effectiveness and functional residential designs higher than timely delivery of service. This probably indicates the importance of quality over timeliness in delivering residential design services. Furthermore, the ranking of the expectations of clients for residential design service may be different from that for construction services. This is because the results of this study show that although architects perceived that clients will rank quality higher than time, the clients themselves ranked time higher than quality. This appears different as that found by Bowen et al. (2002), which shows that for construction services, clients ranked quality higher than time while contractors and consultants, including architects ranked time higher than quality in their perception of client expectation. The difference may have results from the fact that the study by Bowen et al. involved many consultants in the construction industry and was carried out in South Africa, while this study was based on responses of architects and clients and was carried out in Nigeria.

The results of this study also show that the display of creativity did not top the list of the expectations of clients from residential design services in the study area. Interestingly, architects in the study did not also believe that innovation was that important to this category of clients. In fact, architects believed that it was the least of the expectation of these clients from them. This appears to contradict the notion that architects are known for creativity (Brown et al. 2010). It is not clear why a profession set aside by creativity not be expected to deliver creative solutions. This probably sets a limit to the idea of creativity agenda of architectural firms (Emmitt, 1999). It is however possible that clients, who require residential design services, do not require as much innovation as those that require non- residential design services. This however needs to be further investigated.

It is also found that the most important task relating to clients' expectation was cost- effective residential designs. Both clients and architects agreed on this point. What this suggests is that the cost implications of residential designs are very important to clients and should be adequately addressed by architect. This is because it may be a strong point on which the judgment of clients on residential designs 
may be based. An area that architects may also need to address is that of the personal experience they give their clients, since clients ranked this higher than functional designs or timely delivery of service. The architect did not however perceive that the clients did as the results show that architects ranked functional design and timely delivery of service higher than good personal experience as client expectations from them for residential design services.

The differences in scores of clients and architects for clients' expectations suggest that architects may not understand their clients who require designs for residential buildings enough. There may therefore not be adequately addressing client requirements. Specifically, the results suggest that while architects may have been investing excessively in timely delivery of service, cost- effective design and quality service because they perceive that clients attach high importance to these factors, they miss the mark when it comes to other expectations of the clients. One would therefore wonder if these expectations were not clearly communicated, or architects just have preconceptions that they are not willing to change. These results suggest areas where a change in the perceptions of architects of their clients' expectations is needed. This may lead to a change in response, and subsequently better service experience as well as better satisfaction of the clients.

\section{CONCLUSION}

This study has contributed to the service quality literature by identifying the service expectations of residential clients from architectural design services. This probably suggests that dimensions of service expectation may differ with services. This study has been able to reveal how much architects understand the expectations of their clients in search of residential designs in Lagos, Nigeria. The results suggest although architects may not have realized it, the experience they display and well as innovative designs are very important to their residential clients. It is to be noted that data was obtained in Lagos, Nigeria and the result may be context-specific. Similar studies may be carried out in other contexts to ascertain the limits of generalization of the results. This study has however been useful in that it is one of the first attempts to investigate architecture clients' expectations. Architects in the area of study may address these gaps to ensure expectations of this category of clients are adequately met, with the probability of recording higher client satisfaction with residential design services. Specifically, the results show that there may be general misconception of the expectations of clients in search of residential design services. This study has only investigated realistic expectations, which are achievable from the part of the architect. Client requirements are often communicated during a brief session. One may therefore not expect misconceptions or unrealistic expectation as the architect is expected to have been properly briefed on the expectations of clients. The results may therefore suggest that there may be challenges with the briefing process in the study area. Very few studies have however investigated these sessions and how effective they are in communicating client expectations to architects. Further studies may also be required, which addresses other categories of clients in order to draw conclusions on the general expectations of clients for design services. This is because only residential clients were investigated in the study. This study has provided a platform for further research as a result of major limitation posed by the size of the study population and the sample size.

\section{REFERENCES}

Architects Registration Council of Nigeria (ARCON, 2010). Register of Architectural Firms Entitled to Practice in the Federal Republic of Nigeria.

Bowen, P. A., Cattel, K. S., Hall, K. A., Edwards, P. J., and Pearl, R. G. (2002) Perception of Time, Cost and Quality Management on Building Projects. Australian Journal of Construction Economics and Management, 2(2): 48-56.

Boyd, D. and Kerr, E. (1998). An analysis of developer-clients' perception of consultants. In: Hughes, W. (Ed.), Conference Proceeding of the 14th Annual ARCOM Conference, 9-11 September 1998, University of Reading. Association of Researchers in Construction Management, Vol. 1, 88-97.

Brown, A. D., Kornberger, M., Clegg, S. R., and Carter, C. (2010). 'Invisible Walls' and 'Silent Hierarchies': A Case Study of Power Relations in an Architecture Firm. Human Relations Vol. 63 No. 4, 525-549.

Brown, S. W. and Swartz, T. A. (1989) A Gap Analysis of Professional Service Quality. Journal of Marketing, 53(2): 92-98.

Emmitt, S. (1999). Architectural Management in Practice: A Competitive Approach AddisonWesley Longman: Harlow.

George, D. and Mallery, P. (2003). SPSS for Windows Step By Step: A Simple Guide and Reference. 11.0 Update (4th Ed.). Boston: Allyn \& Bacon.

Hui, E. C. M. and Zheng, X. (2010). Measuring customer satisfaction of FM service in housing sector: A structural equation model approach. Facilities, 28(5/6): 306-320. 
Jones, C., Hesterley, W. S., Fladmoe-Lindquist, K., and Borgatti, S. P. (1998) Professional Constellation: How Strategies and Capabilities Influence Collaborative Stability and Change. Organizational Science, 9(3): 396-410.

Lewis, R. K. (1998) Architect? A candid guide to the Profession MIT Press: USA.

Oluwatayo A. A. (2009). A Critical Study of the Practice Characteristics of Architectural Firms in Nigeria. An Unpublished PhD Thesis Submitted to the Department of Architecture, Covenant University.

Oyedele, L. O. and Tham, K. W. (2007) Clients' Assessment of Architects' Performance in Building Delivery Process: Evidence From Nigeria. Building and Environment, 42(5): 2090-2099.
Salehi, M., Alipour, M., and Sharif, M. S. (2009). Service Expectation Gap: Empirical Evidence of Iranian Insurance Company. Serbian Journal of Management, 4(1): 51-63.

Sonne, A. (1999). Determinants of Customer Satisfaction with Professional Services: A Study of Consultant Services, Økonomisk Fiskeriforskning, 9(2): 97-107.

Tang, S. L., Lu, M., and Chan, Y. L. (2003). Achieving Client Satisfaction for Engineering Consulting Firms. Journal of Management in Engineering, ASCE, 19(4): 166-72.

Ziethalm, V. A., Berry, L. L., and Parasuraman, A. (1993). The Nature and Determinants of Customer Expectations of Service. Journal of the Academy of Marketing Sciences, 21(1): 1-12. 